\title{
Key role of mitochondria in cerulenin-mediated apoptosis
}

\author{
SJ Heiligtag ${ }^{1,2}$ R Bredehorst ${ }^{2}$ and KA David ${ }^{\star, 1,2,3}$ \\ 1 Cancer Research Center of Hawaii, University of Hawaii, 1236 Lauhala Street, \\ Honolulu, Hawaii 96813, USA \\ 2 Department of Biochemistry and Molecular Biology, University of Hamburg, \\ Martin-Luther-King-Platz 6, 20146 Hamburg, Germany \\ ${ }^{3}$ Current address: Department of Biochemistry and Molecular Biology, \\ University of Hamburg, Martin-Luther-King-Platz 6, 20146 Hamburg, \\ Germany \\ * Corresponding author: Kerstin A David, PhD, Department of Biochemistry and \\ Molecular Biology, University of Hamburg, Martin-Luther-King-Platz 6, 20146 \\ Hamburg, Germany. Tel: 49-40-42838-2841, Fax: 49-40-42838-2848; \\ E-mail: kerstin.david@geonet.com
}

Received 17.8.01; revised 20.2.02; accepted 18.3.02

Edited by M. Oren

\begin{abstract}
Cerulenin, a fungal metabolite, is known to be a specific inhibitor of fatty acid synthase. Here we report that cerulenin is an effective inducer of apoptosis in different wild-type p53 and mutant p53 tumor cell lines, whereas normal human keratinocytes and fibroblasts are resistant to the apoptotic effect. To get more insight into the mechanisms of how cerulenin induces apoptosis we investigated several signal transduction molecules, including p53, p73, p21/WAF1, Bax, cytochrome $c$, and caspases 3 and 9 . Our data strongly indicate that mitochondria play a key role in the ceruleninmediated pathway. Bax overexpression correlated with the extent of apoptosis and appears to be regulated in a p53independent manner. The significance of the mitochondrial pathway for the cerulenin-mediated apoptosis was confirmed by the rapid mitochondrial release of cytochrome $c$ both in wild-type p53 and mutant cell lines. Interestingly, the rapid release of cytochrome $c$ was not accompanied by a breakdown of the mitochondrial potential. Instead, the complete disruption of the mitochondrial function coincided with the appearance of a p18 $\mathrm{kDa}$ cleavage product of Bax.

Cell Death and Differentiation (2002) 9, 1017-1025. doi:10.1038/ sj.cdd. 4401055
\end{abstract}

Keywords: fatty acid synthase, cerulenin, apoptosis, p53, Bax

Abbreviations: $\mathrm{BCA}$, bicinchoninic acid; $E C L$, enhanced chemiluminescence; FITC, fluorescein isothiocyanate; PARP, poly(ADPribose) polymerase; PTP, permeability transition pore

\section{Introduction}

Cerulenin ((2S,3R)-2,3-epoxy-4-oxo-7,10-dodecadienoylamide), a fungal metabolite, is known as an inhibitor of fatty acid synthase. ${ }^{1,2}$ Previous reports have shown that cerulenin is a cytotoxic agent for several tumor cells and apoptosis has been demonstrated to represent one mechanism of ceruleninmediated cytotoxicity. ${ }^{3,4}$ As reported recently, we were able to confirm the apoptosis-inducing effect of cerulenin in various cell lines by Annexin V-binding and PARP cleavage. ${ }^{5}$ The mode of action of cerulenin, however, remains to be elucidated.

In previous reports it has been hypothesized that the cerulenin-mediated apoptotic effect is due to starvation induced through fatty acid inhibition., ${ }^{1,6,7}$ Subsequent studies demonstrated, however, that apoptosis is not directly triggered by fatty acid starvation, but might be a result from accumulation of the substrate malonyl-CoA. Interestingly, inhibition of acetyl-CoA carboxylase, a component of the fatty acid complex, by exposure to TOFA (5-(tetradecyloxy)-2-furoic acid) proved to be non-toxic to tumor cells. 8,9 This observation demonstrates that the sole inhibition of fatty acid synthesis is not sufficient for triggering apoptosis, a fact that is supported by the data of this study.

In order to get more insight into the mechanisms of cerulenin-induced apoptosis we investigated several signal transduction molecules including p53, p73, p21/ WAF1, Bax, cytochrome $c$, and caspases 9 and 3 . The molecules of the mitochondrial pathway such as Bax and cytochrome $c$ were especially interesting because mitochondria gained more and more importance as mediator of drug-induced apoptosis. ${ }^{10,11}$ Bax, a pro-apoptotic member of the Bcl-2 family, has been shown to play an important role both in inhibiting tumor progression and in promoting the apoptosis of tumor cells in response to chemotherapeutic agents like those used in the treatment of cancer. ${ }^{12,13}$ While the precise function of Bax remains to be clarified, theories include a pore-forming activity in the outer mitochondrial membrane that enables the release of cytochrome $c$ into the cytosol, ${ }^{14,15}$ and a function as a constituent of the permeability transition pore (PTP), which appears to be composed of several proteins located in both inner and outer mitochondrial membranes. ${ }^{16}$ Bax is transcriptionally regulated by $\mathrm{p} 53$, although p53-independent regulatory mechanisms have also been reported. ${ }^{17-19}$

n our study, we provide evidence that mitochondria play a key role in cerulenin-mediated apoptosis. Cerulenin treatment caused a rapid release of cytochrome $c$ from the mitochondrial intramembrane space into the cytosol followed by activation of caspases 9 and 3 . Furthermore, in all cerulenin-sensitive cell lines Bax overexpression was observed. Since this overexpression occured in wild-type p53 as well as in mutant p53 cell lines, Bax appears to be regulated in a p53-independent manner. Based on this observation the apoptosis-inducing capability of cerulenin in the presence of functionally altered p53 may provide urgently needed means to circumvent commonly observed drug resistance problems due to p53 mutations. 


\section{Results}

\section{Cerulenin induces apoptosis in wild-type p53 cell lines and in mutant p53 cell lines}

We examined the cytotoxic effects of cerulenin in twelve cell lines. After $12 \mathrm{~h}$ of incubation with $15 \mu \mathrm{g} / \mathrm{ml}$ of cerulenin dramatic morphological changes with typical signs of apoptosis such as membrane blebbing and loss of adherence were observed in all wild-type p53 neuroblastoma cell lines as well as in mutant p53 HaCaT, A431, and NMB-7 cells.

In contrast, exposure of these cells to $5 \mu \mathrm{g} / \mathrm{ml}$ of cerulenin generated no significant apoptotic signs even 3 days after treatment. Other cell lines including SK-MEL-932, MCF-7, and SK-BR-3, WiDr cells, and normal keratinocytes and fibroblasts exhibited only slight morphological changes even after treatment with $15 \mu \mathrm{g} / \mathrm{ml}$ of cerulenin (data not shown). To confirm these morphological observations, cerulenin-induced apoptosis was subsequently investigated by Annexin V-binding in eight tumor cell lines as well as in normal keratinocytes and fibroblasts. As shown in Figure 1, the neuroblastoma cell lines LAN-1, SK-N-SH, and NMB-7 as well as the transformed keratinocyte cell line $\mathrm{HaCaT}$ were highly sensitive to cerulenin treatment and exhibited more than $75 \%$ specific apoptosis after $18 \mathrm{~h}$ of treatment. Consistent with the morphological observations the breast cancer cell lines SK-BR-3 and MCF-7 yielded only 45 and $25 \%$ specific apoptosis, respectively. No apoptotic effects were observed in WiDr cells, normal human keratinocytes, and normal human fibroblasts (Figure 1). Treatment of HaCaT and LAN-1 cells with c75 $(\alpha-$ methylene- $\gamma$-butyrolacton), another inhibitor of fatty acid synthase, yielded similar apoptotic effects. After 12 hours of incubation with $15 \mu \mathrm{g} / \mathrm{ml}$ of $\mathrm{c} 75$, the Annexin V-binding assay indicated 67 and $62 \%$ specific apoptosis in HaCaT and LAN-1 cells, respectively (data not shown).

\section{The extent of apoptosis does not correlate with the level and inhibition of fatty acid synthase}

In order to determine whether the inhibition of fatty acid synthase might be a trigger of cerulenin-mediated apoptosis, we determined fatty acid expression and fatty acid activity in ten different tumor cell lines as well as in normal human keratinocytes and fibroblasts. Fatty acid synthase levels were determined by densitometric analysis using purified fatty acid synthase as standard (not shown). Fatty acid synthase activity was measured by $\left[{ }^{14} \mathrm{C}\right]$ acetic acid incorporation into cellular lipids as marker. In all investigated cell lines fatty acid synthase expression and fatty acid synthase activity paralleled each other but the levels were quite heterogenous in the various investigated cell lines (Figure 2). The breast carcinoma cell line SK-BR-3 exhibited significantly higher fatty acid synthase expression and activity than any other cell line (Figure 2). However, this cell line revealed only a medium apoptotic effect upon cerulenin treatment (Figure 1). Similar observations were made in different neuroblastoma cell lines. LAN-1 and IMR-32 cells showed relatively high levels of fatty acid synthase, whereas only small amounts of the enzyme complex were seen in SK-N-SH cells. Despite these dramatically different levels of active fatty acid synthase, LAN-1 cells yielded the same amount of specific apoptosis than SK-N-SH cells (Figure 1). In addition, no differences in fatty acid synthase expression and activity were observed in cancer cells and normal cells, that were completely refractory to cerulenin (Figure 2). In summary, the data indicate a lack of

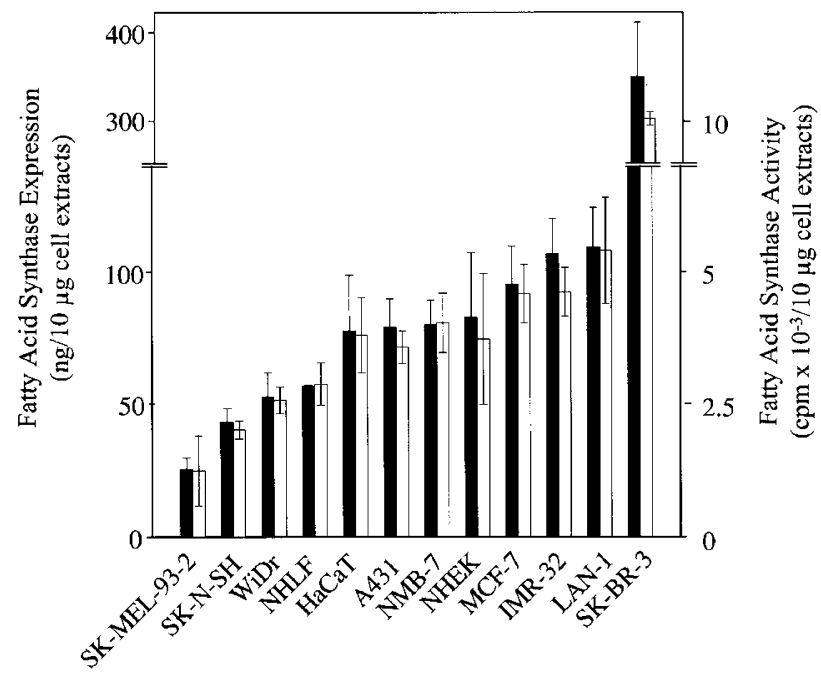

Figure 2 Determination of fatty acid synthase expression and activity in tumor cell lines and normal cells. Fatty acid synthase expression and activity were determined in ten different tumor cell lines and in normal human epidermal keratinocytes (NHEK) and lung fibroblasts (NHLF). Fatty acid synthase expression was determined in cell extracts by densitometric analysis after SDS-PAGE and Western blotting using a monoclonal anti-fatty acid synthase antibody and chemiluminescence for development (black bars). Fatty acid synthase activity was determined by $\left[{ }^{14} \mathrm{C}\right]$ acetic acid incorporation into acylglycerols in intact cells (open bars) 
correlation of the extent of apoptosis with fatty acid expression and fatty acid activity.

To evaluate the effect of fatty acid synthase inhibition on the induction of apoptosis more in detail, cells were treated with different concentrations of cerulenin. After $3 \mathrm{~h}$ of incubation in the presence of $5 \mu \mathrm{g} / \mathrm{ml}$ cerulenin we observed a reduction of fatty acid synthase activity between 40 and $70 \%$ in all twelve cell lines. Further reduction of fatty acid synthase activity could neither be accomplished by increasing the cerulenin concentration to $15 \mu \mathrm{g} / \mathrm{ml}$ nor by extending the length of cerulenin exposure to $6 \mathrm{~h}$. The results for five representative cell lines are shown in Figure 3A. The extent of apoptosis, however increased significantly from $5 \mu \mathrm{g} / \mathrm{ml}$ to $15 \mu \mathrm{g} / \mathrm{ml}$ of cerulenin as shown by nuclear enzyme poly(ADP-ribose) polymerase (PARP)cleavage (Figure $3 \mathrm{~B}$ ). PARP, which has significance as a prototype caspase substrate in apoptotic processes, is proteolytically processed in a dose-dependent manner into its characteristic $89 \mathrm{kDa}$ fragment, which is shown in three

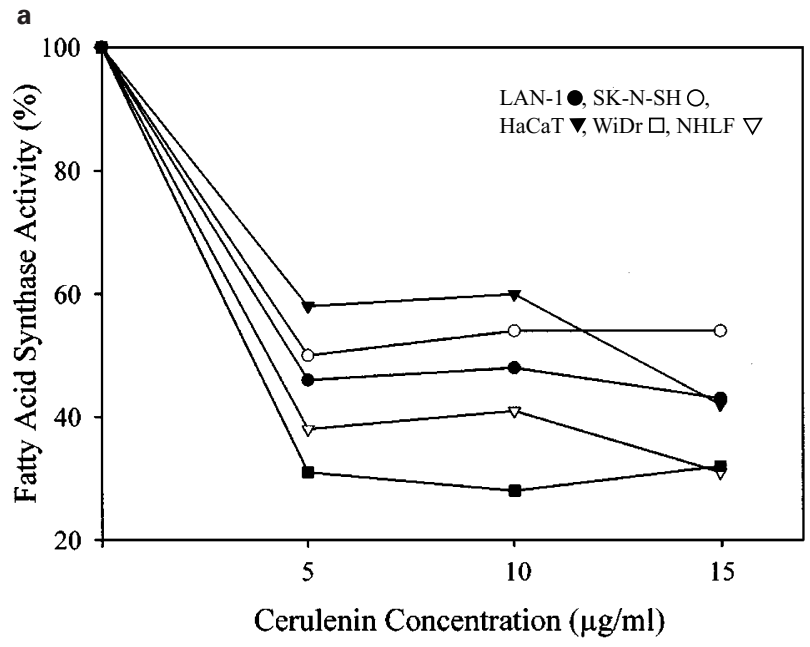

b

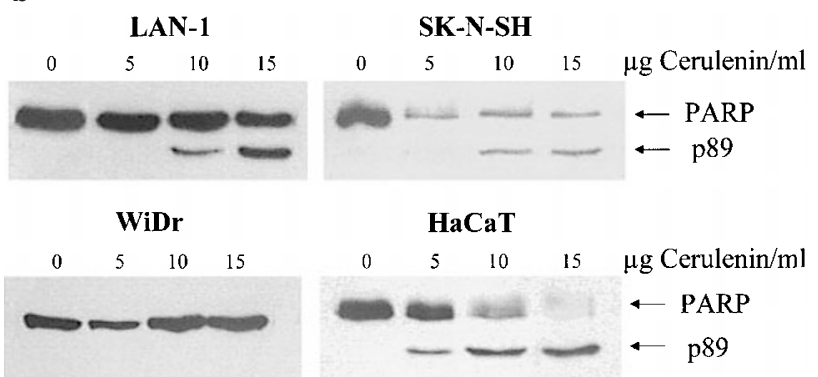

Figure 3 (A) Cerulenin-mediated inhibition of fatty acid synthase activity. Cultivated cells were exposed to different cerulenin concentrations $(5,10$ and $15 \mu \mathrm{g} / \mathrm{ml}$ ) for $3 \mathrm{~h}$. Fatty acid synthase acitvity was subsequently measured by incorporation of $\left[{ }^{14} \mathrm{C}\right]$ acetic acid into acylglycerols. Four tumor cell lines (LAN1 filled circle, SK-N-SH circle, HaCaT filled triangle, WiDr filled square) and normal human lung fibroblasts (NHLF triangle) are shown, representative for all twelve cell lines tested. Fatty acid synthase activity is expressed as percent of the fatty acid synthase activity of each cell line without inhibition. (B) Cerulenin-mediated PARP cleavage. After exposure of four tumor cell lines (LAN-1, SK-N-SH, WiDr, HaCaT) to 5,10 and $15 \mu \mathrm{g} / \mathrm{ml}$ cerulenin for $18 \mathrm{~h}$, cleavage of PARP is shown by immunoblot analysis demonstrating the generation of the $89 \mathrm{kDa}$ PARP cleavage fragment. The ECL system was used for development representative cerulenin-sensitive cell lines (Figure 3B). Consistent with our previous data, no cleavage product was observed in WiDr cells (Figure 3B). Collectively, these data indicate that at higher concentrations of cerulenin other mechanisms than the sole inhibition of fatty acid synthase appear to be responsible for the induction of apoptosis.

\section{Cerulenin induces changes in expression levels of p53, Bax, and p21/WAF1}

To determine whether p53 and the p53 regulated proapoptotic protein Bax as well as the cyclin-dependent kinase inhibitor p21/WAF1 have a regulatory role in the ceruleninmediated apoptosis, we first investigated changes of these proteins in four wild-type p53 cell lines (LAN-1, SK-N-SH, MCF-7, A-172) after 12 and $24 \mathrm{~h}$ of cerulenin treatment (Figure 4). We found p53 accumulation in all cell lines already after 12 h of incubation. Interestingly, two cell lines (SK-N-SH, MCF-7) generated an additional anti-p53 reactive band of approximately $40 \mathrm{kDa}$ after $12 \mathrm{~h}$ of cerulenin treatment, which might be a cleavage product of p53. Since cleavage of p53 has been described to occur occasionally after DNA strand damages, ${ }^{20}$ the additional band points to cerulenin as a DNAdamaging agent. However, other experiments did not confirm this point of view, yet. Although cerulenin induced an accumulation of p53, levels of p21/WAF1 were either downregulated (SK-N-SH, MCF-7) or not detectable (LAN-1, A-172). In contrast, Bax levels were significantly increased in the two neuroblastoma cell lines LAN-1 and SK-N-SH but not in MCF-7 and A-172 cells (Figure 4). Furthermore, a significant processing of p21 Bax into an $18 \mathrm{kDa}$ cleavage product was observed in the Bax overexpressing cell lines LAN-1 and SK-N-SH. A weak band was also detectable in MCF-7 cells after $24 \mathrm{~h}$ of incubation. The function of $\mathrm{p} 18 \mathrm{Bax}$ in the signaling process remains to be determined.

In all four mutant p53 cell lines (NMB-7, HaCaT, SK-BR3 , WiDr), no accumulation of p53 was observed after cerulenin-treatment (Figure 5). However, although p53 is functionally affected in these cell lines, p21/WAF1 levels were increased after $12 \mathrm{~h}$ of cerulenin treatment in all investigated cell lines, suggesting a p53-independent regulation of p21/WAF1. In addition, a p53-independent increase in the expression of Bax was observed in the cerulenin-sensitive cell lines NMB-7 and HaCaT cells, whereas no increase in Bax levels was detectable in SKBR-3 cells and WiDr cells, both of which exhibit a weak and non apoptotic response. Interestingly, the additional $18 \mathrm{kDa}$ cleavage product, which was also observed in LAN-1 and SK-N-SH cells (Figure 4), was only detectable in NMB-7 cells but not in HaCaT cells. In summary, these data show that Bax overexpression correlates significantly with the extent of apoptosis in all cerulenin-sensitive cell lines, pointing to an important role of Bax in the apoptotic pathway.

\section{p73 does not accumulate in response to cerulenin treatment}

Since cerulenin-induced overexpression of Bax is apparently p53-independent, we examined the response of p73 on cerulenin treatment. $p 73$, a member of the p53 family, has 
Wild-Type p53 Cell Lines

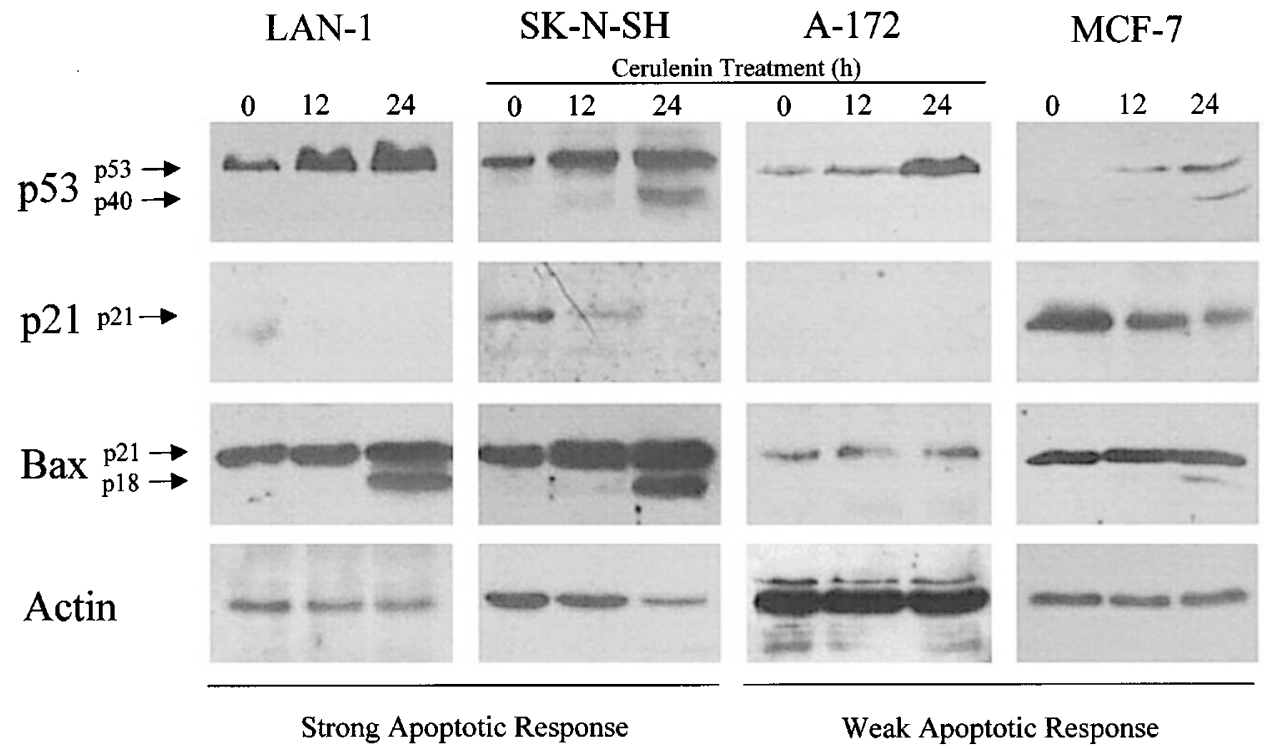

Figure 4 Expression of p53, p21/WAF1 and Bax in wild-type p53 cell lines. LAN-1, SK-N-SH, A-172, and MCF-7 cells were incubated in the absence or presence of $15 \mu \mathrm{g} / \mathrm{ml}$ of cerulenin for 12 and $24 \mathrm{~h}$. Cell extracts were seperated on a $13 \%(\mathrm{w} / \mathrm{v})$ SDS-PAGE. Detection of p53, p21/WAF1, and Bax was performed by immunoblotting using the specific antibodies against these proteins and the ECL system. An antibody against actin was used for the control of equal loading

been described as a specific and strong inducer of the bax gene. We investigated the expression of $p 73 \alpha$ and $\beta$ in the wild-type p53 cell line LAN-1 and the mutant p53 cell line $\mathrm{HaCaT}$ after cerulenin treatment for 12 and $24 \mathrm{~h}$. As evident from Figure 6, p73 $\alpha$ is expressed in LAN-1 cells as well as in $\mathrm{HaCaT}$ cells, but the level of p73 $\alpha$ did not increase in both cell lines after 12 and $24 \mathrm{~h}$ of cerulenin treatment (Figure 6). Expression of $\mathrm{p} 73 \beta$ was not detectable under the experimental conditions.

\section{Cytochrome $c$ release is an early event in the cerulenin-mediated apoptosis and not accompanied by a breakdown of the mitochondrial potential $(\Delta \Psi)$}

To explore whether cytochrome $c$ might be an effector molecule in the cerulenin-mediated apoptotic pathway, we analyzed its cytosolic release in LAN-1 cells and $\mathrm{HaCaT}$ cells at $0,4,6$ and $12 \mathrm{~h}$ after exposure cells to cerulenin. Figure 7 shows that cytochrome $c$ release from the mitochondria into the cytosol is an early event in both cell lines. It was detectable after only $4 \mathrm{~h}$ of cerulenin treatment, preceding upregulation of Bax. A similar observation was made with c75. LAN-1 cells exposed to $15 \mu \mathrm{g} / \mathrm{ml} \mathrm{c75}$ exhibited a significant cytochrome $c$ release as early as $6 \mathrm{~h}$ after treatment (not shown).

As described in other studies, cytochrome $c$ can be released as a result of the opening of the PTP which is accompanied by loss of $\Delta \Psi .^{10,21,22}$ However, cytochrome $c$ release precedes $\Delta \Psi$ loss, indicating that PTP opening is not required for the release of cytochrome $c$. Furthermore, a complete breakdown of the mitochondrial potential was only detectable in LAN-1 cells (Figure 8). Interestingly, the breakdown of the mitochondrial potential coincided with the appearance of a p18 $\mathrm{kDa}$ cleavage product of Bax in LAN1 cells (Figure 4).

\section{Cerulenin treatment leads to activation of caspases 3 and 9 .}

Cytochrome $c$ in combination with the apoptotic protease activating factor 1 (APAF-1) stimulates caspase 9 in the presence of ATP, resulting in activation of caspase 3 , which has been shown to cleave several substrates responsible for apoptotic features. ${ }^{23}$ As shown in Figure 9, the $10 \mathrm{kDa}$ cleavage product of caspase 9 was observed after $6 \mathrm{~h}$ in $\mathrm{HaCaT}$ cells when treated with cerulenin, which is consistent with the early release of cytochrome $c$ into the cytosol. Complete processing of caspase 9 was noted after $12 \mathrm{~h}$ of incubation. A similar kinetic was observed in LAN-1 cells. However, probably due to the lower amount of caspase 9 in LAN- 1 cells, the band of processed caspase 9 is only very faint after $6 \mathrm{~h}$ of incubation. Figure 9 shows that processing of caspase 3 into 17 and $21 \mathrm{kDa}$ cleavage products was detectable in both cell lines, although some hours earlier in HaCaT cells.

\section{Discussion}

The inhibition of fatty acid synthase is not the main trigger for the induction of apoptosis

In previous studies it has been suggested that starvation due to inhibition of fatty acid synthesis might be responsible for the cytotoxic effects that cerulenin executes on tumor cells. ${ }^{1,6,24}$ However, the lack of cytotoxic effects in tumor cells incubated in the presence of TOFA, an acetyl-CoA carboxylase inhibitor, 
Mutant p53 Cell Lines

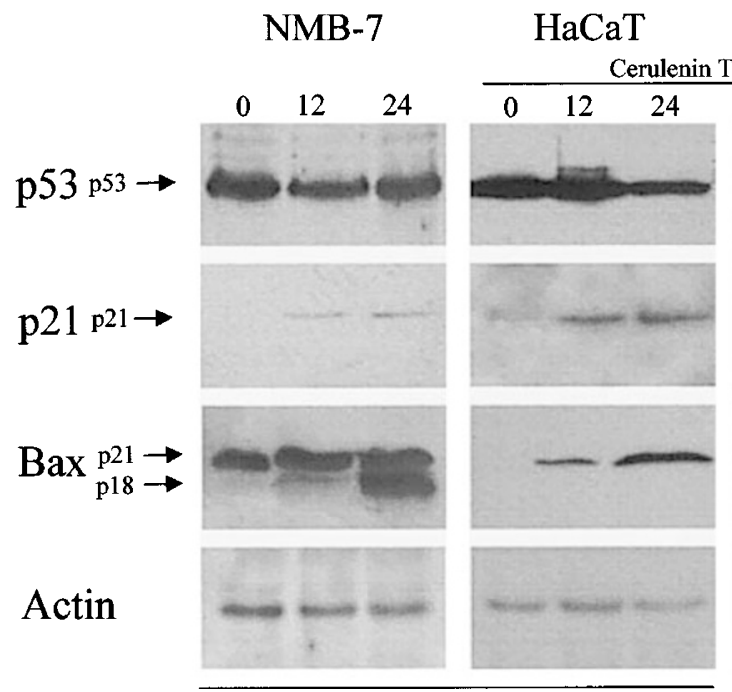

Strong Apoptotic Response
SK-BR-3

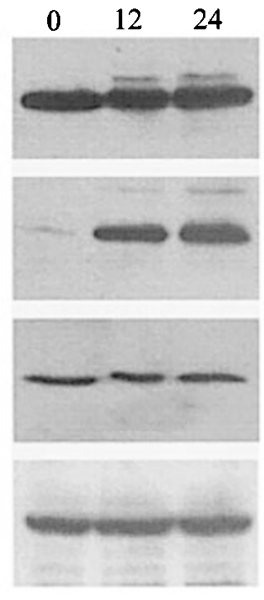

Weak Apoptotic Response

Figure 5 Expression of p53, p21/WAF1 and Bax in mutant p53 cell lines. NMB-7, HaCaT, SK-BR-3, and WiDr cells were incubated in the absence or presence of $15 \mu \mathrm{g} / \mathrm{ml}$ of cerulenin for 12 and $24 \mathrm{~h}$. Detection of p53, p21/WAF1, Bax , and actin was performed as described under Figure 4

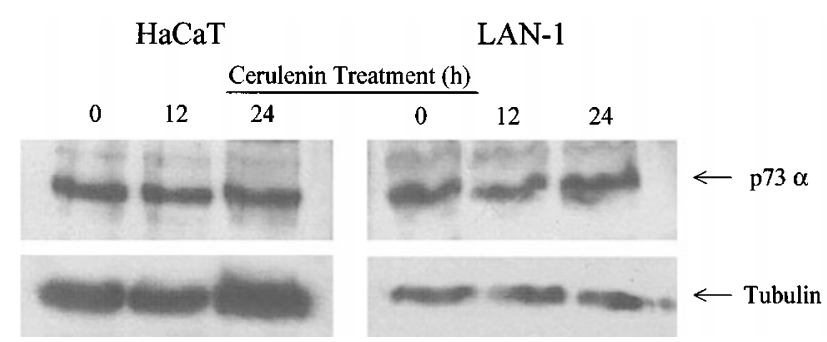

Figure 6 Expression of p73 in HaCaT and LAN-1 cells. LAN-1 and HaCaT cells were incubated in the absence or presence of $15 \mu \mathrm{g} / \mathrm{ml}$ of cerulenin for 12 and $24 \mathrm{~h}$. Detection of $\mathrm{p} 73$ was performed by immunoblotting using the specific antibodies against these proteins and the ECL system. An antibody against actin was used for the control of equal loading

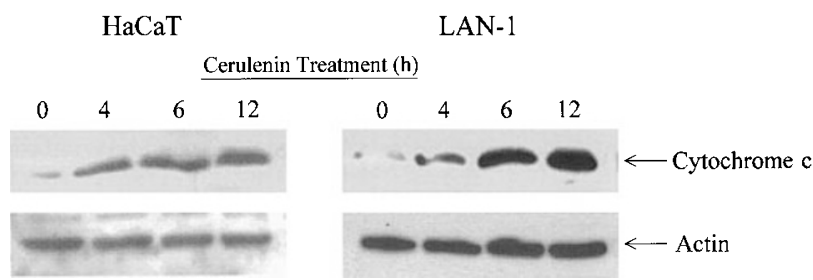

Figure 7 Cerulenin-mediated cytochrome $c$ release into the cytosol. LAN-1 and $\mathrm{HaCaT}$ cells were incubated in the absence or presence of $15 \mu \mathrm{g} / \mathrm{ml}$ of cerulenin for 4,6 and $12 \mathrm{~h}$. Cytosolic fractions were analyzed by immunoblotting using a polyclonal rabbit anti-cytochrome $c$ antibody. An antibody against actin was used for the control of equal loading

indicated that other mechanisms than starvation are responsible for cerulenin-induced apoptosis..$^{4,8,9}$ The data of our study confirm this conclusion, and several lines of evidence suggest that inhibition of fatty acid synthesis is not the main
LAN-1

$\mathrm{HaCaT}$

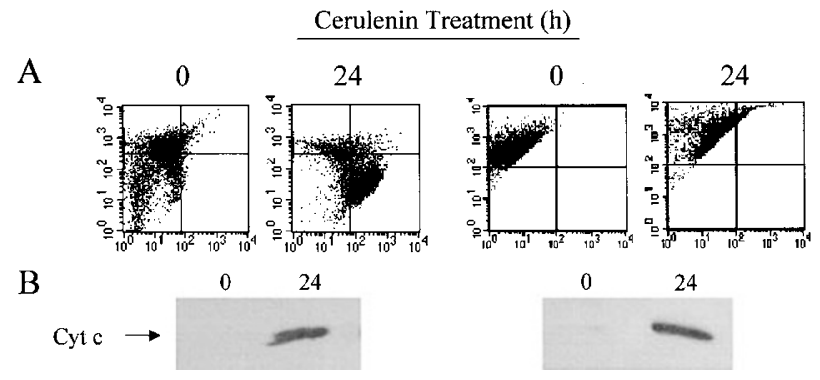

Figure 8 Influence of cerulenin-treatment on the mitochondrial potential. (A) LAN- 1 and $\mathrm{HaCaT}$ cells were treated with $15 \mu \mathrm{g} / \mathrm{ml}$ cerulenin for $24 \mathrm{~h}$. The mitochondrial potential was quantified by cytofluorometric analysis. Staining was performed with the cationic lipophilic fluorochrome JC-1. (B) LAN-1 and $\mathrm{HaCaT}$ cells were incubated with cerulenin $(15 \mu \mathrm{g} / \mathrm{ml})$ for $24 \mathrm{~h}$. Cytosolic fractions were analyzed by Western blot analysis using a polyclonal rabbit anti-cytochrome $c$ antibody

trigger for the cerulenin-mediated apoptosis. First, we did not observe any correlation between the extent of fatty acid synthase expression and the apoptotic response. Second, the inhibition of fatty acid synthase and the induction of apoptosis are supported by differential dose requirements. Fatty acid synthase inhibition achieved with $5 \mu \mathrm{g} / \mathrm{ml}$ of cerulenin ranged between 40 and $70 \%$ in all cell lines investigated in this study. A further increase in the cerulenin concentration was without effect on the remaining fatty acid synthase activity. At $5 \mu \mathrm{g} / \mathrm{ml}$ cerulenin, however, both morphological and biochemical signs of apoptosis including Annexin V-binding and PARP cleavage were barely or not at all detectable, even after 3 days of cerulenin treatment. 


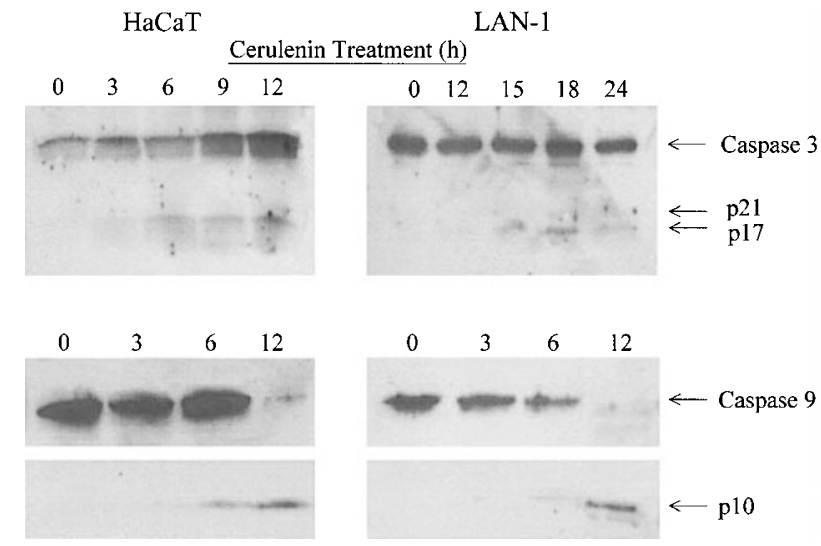

Figure 9 Activation of caspases after cerulenin treatment. LAN-1 and HaCaT cell extracts were analyzed by Western blotting after treatment of cells with cerulenin $(15 \mu \mathrm{g} / \mathrm{ml})$ for the indicated times. A polyclonal rabbit antibody against caspase 9 was used for the detection of the proform (48 $\mathrm{kDa})$ and the cleavage product of caspase $9(10 \mathrm{kDa})$. For the detection of caspase 3 activation a polyclonal rabbit antibody against caspase 3 was used. Intact caspase 3 ( $32 \mathrm{kDa})$ is cleaved into two fragments of 17 and $21 \mathrm{kDa}$

Based on these observations, cerulenin exerts at least two different activities at low and high concentrations. Inhibition of fatty acid synthase by low concentrations of cerulenin appears to be necessary but not sufficient for the induction of significant apoptosis, whereas at higher concentrations cerulenin exerts apparently a second activity leading to substantial apoptosis.

\section{Functional p53 is not essential for the induction of apoptosis}

Since both wild-type p53 cells and mutant p53 cell lines revealed similar strong apoptotic responses, ceruleninmediated apoptosis appears to be regulated in a p53independent manner. It has been recently discussed that p53 accumulation functions as a protector mechanism against cerulenin-mediated apoptosis, ${ }^{4}$ probably due to the induction of p21/WAF1, which promotes growth arrest and exerts a protective effect after fatty acid synthase inhibition. ${ }^{4}$ In contrast, we could show that p53 accumulated in wild-type p53 cells in response to cerulenin whereas levels of p21/ WAF1 remained unchanged or even decreased. This is consistent with our observation that cerulenin does not induce a G1 cell cycle arrest, which would have been typical for a p53-mediated stress response. Instead, cerulenin induced Sphase arrest in all cell lines investigated so far. Surprisingly, p21/WAF1 accumulated in mutant p53 cell lines, suggesting a translational and/or posttranslational regulatory mechanism of p21WAF1 as it has been discussed. ${ }^{25}$ After cerulenin treatment the regulation of Bax, another transcriptional target of p53, appears also to be independent of p53, since overexpression of Bax was observed in wild-type p53 as well as in mutant p53 cell lines. It should be noted that p53independent transcriptional regulation of Bax has also been reported by other groups. ${ }^{17-19}$ One likely regulatory candidate is p73, a newly identified p53 family homologue with remarkable sequence similarity to $p 53 .{ }^{26,27}$ Due to significant homology to p53, p73 activates various p53 responsive promoters and induces tumor cell apoptosis. ${ }^{28}$ The lack of accumulation, however, suggests that p73 does not play an essential role as a mediator in the cerulenin-mediated apoptosis. $^{29}$

\section{Mitochondria are apparently the key player in cerulenin-mediated apoptosis}

The significant correlation between Bax overexpression and the extent of apoptosis in two wild-type p53 cell lines as well as in two mutant p53 cell lines points to an important role of the proapoptotic protein Bax in cerulenin-mediated apoptosis. This is in accordance with other studies demonstrating the potential importance of Bax in mediating chemosensitivity. ${ }^{17,30}$ For example, a significant correlation between endogenous levels of Bax protein and sensitivity to both doxorubicin and actinomycin $D$ has been described for neuroblastoma cells. ${ }^{30}$ A puzzling observation, however, was the release of cytochrome $c$ in wild-type p53 LAN-1 cells as well as in the mutant p53 cell line HaCaT several hours before Bax overexpression. Bax has been proposed to form pores into the outer mitochondrial membrane that enables release of cytochrome $c$ from the mitochondria into the cytoplasm. ${ }^{14,31}$ Since at the time of cytochrome $c$ release we observed Bax associated with the mitochondria (not shown), conformational changes of Bax might be responsible for the ability of Bax to release cytochrome $c$ as hypothesized by other investigators. ${ }^{32,33}$ It should be noted, however, that the release of cytochrome $c$ by a passive process due to swelling of the mitochondria is also possible. ${ }^{10}$ While the function of Bax in cytochrome $c$ release requires further investigation, Bax overexpression may also be important for blocking the function of anti-apoptotic molecules such as Bcl-2, which is significantly upregulated after $15 \mathrm{~h}$ of cerulenin treatment (not shown).

Interestingly, the rapid release of cytochrome $c$ was not accompanied by a breakdown of the mitochondrial potential $(\Delta \Psi)$, indicating that opening of the permeability transition pore is not involved in this process. This is in accordance with the data of other recent studies describing the release 
of cytochrome $c$ from mitochondria as a well controlled event independently of the opening of PTP. ${ }^{33}$ The fact that the breakdown of $\Delta \Psi$ was only observed in LAN-1 cells led to the suggestion that other mechanisms than the opening of the permeability transition pores are responsible for the breakdown. One possible mechanism could involve the $18 \mathrm{kDa}$ cleavage product of Bax, which was detectable in LAN-1 cells but not in HaCaT cells, and occurred simultaneously with the breakdown of $\Delta \Psi$ (not shown). The cleavage of full-length p21 Bax into p18 Bax has already been described for other systems, although the meaning of this mechanism is still obscure. ${ }^{22,34}$ One intriguing function of p18 Bax could be the creation of pores in the inner mitochondrial membrane leading to a change in $\Delta \Psi$.

In conclusion, our data demonstrate that cerulenin is a potent apoptosis-inducing drug in different wild-type p53 and mutant tumor cells. Apparently, mitochondria play a key role in the cerulenin-mediated signal transduction pathway, although it remains to be investigated whether cerulenin directly influences the mitochondrial function or through activation of other signaling molecules. Bax overexpression as well as its processing into p18 Bax occurred in a p53-independent manner and appears to have an important regulatory role in the cerulenin-mediated apoptotic pathway. Due to this property, cerulenin provides the potential to kill tumor cells which display drug resistance as a result of p53-mutations.

\section{Materials and Methods}

\section{Human cell lines}

Human neuroblastoma cell lines were obtained from RC Seeger (LAN1; University of California, Los Angeles, USA), ${ }^{35}$ N.-K.V. Cheung (NMB-7; Memorial Sloan-Kettering Cancer Center, New York), ${ }^{36}$ and the American Type Culture Collection (IMR-32, SK-N-SH). The human melanoma cell line SK-MEL-93-2 has been described. ${ }^{37}$ The human colon carcinoma cell line WiDr was supplied by $\mathrm{H}$ Kalthoff (University of Kiel, Germany), ${ }^{38}$ the human breast cancer cell lines MCF-7 and SK-BR-3 as well as the human skin carcinoma cell line A431 were obtained from the American Type Culture Collection. The human transfomed keratinocyte cell line $\mathrm{HaCaT}$ was kindly provided by the Department of Dermatology, University Hamburg, Germany. ${ }^{39}$ All cells were cultivated in RPMI 1640 supplemented with $10 \%(\mathrm{v} / \mathrm{v})$ heatinactivated fetal calf serum, penicillin $(100 \mathrm{IU} / \mathrm{ml})$, and streptomycin $(100 \mu \mathrm{g} / \mathrm{ml}) .{ }^{40}$ All cell culture reagents were obtained from Gibco Life Technologies (Grand Island, NY, USA). Normal human epidermal keratinocytes (NHEK) and normal human lung fibroblasts (NHLF) were from Clonetics (Walkersville, MD, USA) and were cultured according to the supplier's instructions.

\section{Expression of fatty acid synthase in different cell lines}

Cell extracts of the various tumor cell lines (LAN-1, NMB-7, IMR-32, SK-N-SH, HaCaT, A431, WiDr, SK-MEL-93-2, MCF-7, SK-BR-3) and the normal human keratinocytes and fibroblasts were prepared by treatment with lysis buffer $(20 \mathrm{mM}$ Tris- $\mathrm{HCl}, 5 \mathrm{mM}$ EDTA, $150 \mathrm{mM}$ $\mathrm{NaCl}, 1 \%(\mathrm{v} / \mathrm{v})$ Triton-X-100, 1\% (v/v) Complete ${ }^{\mathrm{TM}}, \mathrm{pH}$ 8.3). After removal of insoluble components by centrifugation, the total protein concentrations were measured in triplicate by BCA-assay. For quantification experiments, triplicate samples of cell extracts (each containing $10 \mu \mathrm{g}$ total protein) and a serial dilution of purified fatty acid synthase (10 to $400 \mathrm{ng}$ ) were separated on $7.5 \%$ (w/v) SDS-PAGE. Subsequently, the proteins were electrophoretically transferred $(2 \mathrm{~h}$, 50 Volt) onto a PVDF-membrane (Millipore). Immunoblotting was performed with a monoclonal anti-fatty acid synthase antibody (Transduction Laboratories, San Diego, CA, USA) and a horseradish peroxidase-conjugated anti-mouse IgG antibody (Amersham Pharmacia Biotech). The blots were developed by chemiluminescence (ECL; Pierce). The amount of fatty acid synthase was quantitated by densitometry using the 1D Image Analysis Software (Eastman Kodak, Rochester, NY, USA).

\section{Measurement of fatty acid synthase activity and fatty acid synthase inhibition}

Cells $\left(1 \times 10^{5}\right)$ were plated in triplicate in 24-well plates (E\&K Scientific, Saratoga, CA, USA). After $18 \mathrm{~h}$ of growth, each well was incubated with $1.8 \times 10^{4} \mathrm{~Bq}\left[1-{ }^{14} \mathrm{C}\right]$ acetic acid, sodium salt $(200 \mu \mathrm{Ci} /$ $\mathrm{ml}$; Amersham Pharmacia Biotech) for $2 \mathrm{~h}$. The cells were harvested, washed with PBS, and lysed in $50 \mu$ l hypotonic lysis buffer ( $1 \mathrm{mM} \mathrm{DTT}$, $1 \mathrm{mM}$ EDTA, $20 \mathrm{mM}$ Tris- $\mathrm{HCl}, \mathrm{pH}$ 7.5). The lipids were extracted for $30 \mathrm{~min}$ with $1 \mathrm{ml}$ chloroform/methanol $2: 1(\mathrm{v} / \mathrm{v})$ and separated from the insoluble DNA and proteins by centrifugation at 14000 r.p.m. for $10 \mathrm{~min}$. The lipid-containing phase was washed three times with PBS, and $\left[{ }^{14} \mathrm{C}\right]$-labeled lipids were quantitated in a liquid scintillation counter (Tricarb 2900 TR; Packard, Meriden, CT). The c.p.m. $/ 10^{5}$ cells was converted into c.p.m./ $\mu \mathrm{g}$ cell extract by determining the total protein concentration in a cell extract derived from $10^{5}$ cells. For fatty acid synthase inhibition experiments, cells were treated with cerulenin at concentrations of 5,10 and $15 \mu \mathrm{g} / \mathrm{ml}$ for $3 \mathrm{~h}$ prior to the addition of $\left[{ }^{14} \mathrm{C}\right]$ acetic acid. Cerulenin (Sigma, St. Louis, MO, USA) was solubilized in DMSO at $5 \mathrm{mg} / \mathrm{ml}$ as a stock solution. Control cells were treated with DMSO without cerulenin.

\section{Western blot analysis}

For the detection of Bax, poly(ADP-ribose) polymerase (PARP), and fatty acid synthase, cells were lysed with $20 \mathrm{mM}$ Tris- $\mathrm{HCl}, 5 \mathrm{mM}$ EDTA, 1\% (v/v) Triton-X-100, 1\% (v/v) Complete ${ }^{\mathrm{TM}}, \mathrm{pH} 8.3$, centrifuged, and subsequently analyzed for total protein concentrations by BCA assay. For the detection of p53, p73 and p21/WAF1, complete cell extracts were made by direct solubilization with Laemmli sample buffer. ${ }^{41}$ Equal amounts of protein were separated by 7.5 or $13 \%(\mathrm{w} / \mathrm{v})$ SDS - PAGE and electroblotted onto a PVDF membrane. After blocking with $5 \%(\mathrm{w} / \mathrm{v})$ non-fat dry milk in washing buffer $(50 \mathrm{mM}$ Tris- $\mathrm{HCl}, 150 \mathrm{mM} \mathrm{NaCl}, 0.3 \%$ (v/v) Tween-20, pH 7.5) immunodetection was done using a rabbit anti-PARP antibody (Roche), a rabbit antiBax antibody (Transduction Laboratories), a mouse anti-fatty acid synthase antibody (Pharmingen, San Diego, CA, USA), a rabbit antiGADD153 antibody (Santa Cruz, Santa Cruz, CA, USA), a mouse antip21/WAF1 (Oncogene, Cambridge, MA, USA), a mouse anti-p53 antibody (Transduction Laboratories), or a mouse anti-p73 antibody (Oncogene) respectively. A goat anti-mouse IgG (Sigma) or goat antirabbit IgG (Sigma) conjugated with horseraddish peroxidase was used as secondary antibody. The development was performed by ECL.

\section{Cytofluorometric determination of apoptotic cells by annexin $\mathrm{V}$}

For Annexin V-staining, cerulenin-treated cells $\left(1 \times 10^{5}\right)$ were washed in PBS and incubated with $5 \mu$ of Annexin V-FITC (Transduction Laboratories) and $20 \mu \mathrm{l}$ propidium iodide $(50 \mu \mathrm{g} / \mathrm{ml})$ for $15 \mathrm{~min}$ at room 
temperature (Transduction Laboratories). Quantification of apoptotic cells was performed by flow cytometry using a FACScan. Annexin Vpositive cells that did not take up propidium iodide were identified as early apoptotic, whereas Annexin V-positive cells that could also be stained with propidium iodide were classified as late apoptotic. ${ }^{42}$ The combined percentage of both cell populations was used to calculate the extent of apoptosis after subtraction of corresponding background values.

\section{Assessment of the mitochondrial potential $\left(\Delta \Psi_{m}\right)$}

Changes in the mitochondrial membrane potential were measured by flow cytometry using JC-1 (5,5',6,6'-tetrachloro-1,1',3,3'-tetraethylbenzimidazolyl-carbocyanine iodide; Molecular Probes, Eugene, OR, USA). After incubation with or without cerulenin for indicated times, $1 \times 10^{6}$ cells were resuspended in medium and incubated with $\mathrm{JC}-1$ at a final concentration of $10 \mu \mathrm{M}$ at $37^{\circ} \mathrm{C}, 5 \% \mathrm{CO}_{2}$ for $20 \mathrm{~min}$. Both red (FL-2) and green (FL-1) fluorescence emissions were analyzed using a FACScan (Becton Dickinson). JC-1 forms aggregates in cells with a high FL-2 fluorescence indicating a normal $\Delta \Psi_{\mathrm{m}}$. Loss of $\Delta \Psi_{\mathrm{m}}$ results in a gain in FL-1 fluorescence due to the monomeric state of the dye. ${ }^{43}$

\section{Preparation of cytosolic extracts for detection of cytochrome $c$ release}

For the preparation of mitochondria and cytosolic extracts the ApoAlert Cell Fractionation Kit (Clontech) was used. LAN-1 and HaCaT cells $\left(4 \times 10^{6}\right)$ were incubated with cerulenin for $24 \mathrm{~h}$. Subsequently, the cells were collected and fractionated according to the manufacturer's instructions. Cytochrome $c$ release into the cytososl was detected by Western blotting.

\section{Acknowledgments}

This work was supported by a grant from the Hawaii Community Foundation No. 20000633 (to KA David). SJ Heiligtag was the recipient of a predoctoral fellowship from the Fonds der Chemischen Industrie, Germany.

\section{References}

1. Kuhajda FP, Jenner K, Wood FD, Hennigar RA, Jacobs LB and Dick JD (1994) Fatty acid synthesis: a potential selective target for antineoplastic therapy. Proc. Natl. Acad. Sci. USA 91: 6379-6383

2. Funabashi $\mathrm{H}$, Kawaguchi A, Tomoda H, Omura S, Okuda S and Iwasaki S (1989) Binding site of cerulenin in fatty acid synthetase. J. Biochem. (Tokyo) 105: 751 755

3. Pizer ES, Jackisch C, Wood FD, Pasternack GR, Davidson NE and Kuhajda FP (1996) Inhibition of fatty acid synthesis induces programmed cell death in human breast cancer cells. Cancer Res. 56: 2745-2747

4. Li JN, Gorospe M, Chrest FJ, Kumaravel TS, Evans MK, Han WF and Pizer ES (2001) Pharmacological inhibition of fatty acid synthase activity produces both cytostatic and cytotoxic effects modulated by p53. Cancer Res. 61: 1493-1499

5. David K, Heiligtag S, Bredehorst R and Vogel C-W (2000) Cerulenin induces apoptosis in human neuroblastoma cells. Proc. Amer. Assoc. Cancer Res. 41 A2646

6. PizerES, Wood FD, Pasternack GR and Kuhajda FP (1996) A target for cytotoxic antimetabolites in HL60 promyelocytic leukemia cells. Cancer Res. 4: 745-751

7. Furuya Y, Akimoto S, Yasuda K and Ito H (1997) Apoptosis of androgenindependent prostate cell line induced by inhibition of fatty acid synthesis. Anticancer Res. 17: 4589-4593

8. Gabrielson EW, Pinn ML, Testa JR and Kuhajda FP (2001) Increased fatty acid synthase is a therapeutic target in mesothelioma. Clin. Cancer Res. 7: 153-157
9. Pizer ES, Thupari J, Han WF, Pinn ML, Chrest FJ, Frehywot GL, Townsend CA and Kuhajda FP (2000) Malonyl-coenzyme-A is a potential mediator of cytotoxicity induced by fatty-acid synthase inhibition in human breast cancer cells and xenografts. Cancer Res. 60: 213-218

10. Kroemer $G$ and Reed JC (2000) Mitochondrial control of cell death. Nat. Med. 6 : 513-519

11. Grad JM, Cepero E and Boise LH (2001) Mitochondria as targets for established and novel anti-cancer agents. Drug Resist. Updat. 4: 85-91

12. Bargou RC, Daniel PT, Mapara MY, Bommert K, Wagener C, Kallinich B, Royer $\mathrm{HD}$ and Dorken B (1995) Expression of the bcl-2 gene family in normal and malignant breast tissue: low bax-alpha expression in tumor cells correlates with resistance towards apoptosis. Int. J. Cancer 60: 854-859

13. McCurrach ME, Connor TM, Knudson CM, Korsmeyer SJ, Lowe SW (1997) Baxdeficiency promotes drug resistance and oncogenic transformation by attenuating p53-dependent apoptosis. Proc. Natl. Acad. Sci. USA 94: 23452349

14. Schlesinger PH, Gross A, Yin XM, Yamamoto K, Saito M, Waksman G and Korsmeyer SJ (1997). Comparison of the ion channel characteristics of proapoptotic BAX and antiapoptotic BCL-2. Proc. Natl. Acad. Sci. USA 94: 11357-11362

15. Schendel SL, Montal M and Reed JC (1998). Bcl-2 family proteins as ionchannels. Cell Death Differ. 5: 372-380

16. Marzo I, Brenner C, Zamzami N, Jurgensmeier JM, Susin SA, Vieira HL, Prevost MC, Xie Z, Matsuyama S, Reed JC and Kroemer G (1998) Bax and adenine nucleotide translocator cooperate in the mitochondrial control of apoptosis. Science 281: 2027-2031

17. Strobel T, Swanson L, Korsmeyer S and Cannistra SA (1996) BAX enhances paclitaxel-induced apoptosis through a p53-independent pathway. Proc. Natl. Acad. Sci. USA 93: 14094-14099

18. Knudson CM, Johnson GM, Lin Y and Korsmeyer SJ (2001) Bax accelerates tumorigenesis in p53-deficient mice. Cancer Res. 61: 659-665

19. Fulda S, Friesen C, Los M, Scaffidi C, Mier W, Benedict M, Nunez G, Krammer $\mathrm{PH}$, Peter ME and Debatin KM (1997). Betulinic acid triggers CD95 (APO-1/Fas)and p53-independent apoptosis via activation of caspases in neuroectodermal tumors. Cancer Res. 57: 4956-4964

20. Molinari M, Okorokov AL and Milner J (1996) Interaction with damaged DNA induces selective proteolytic cleavage of p53 to yield $40 \mathrm{kDa}$ and $35 \mathrm{kDa}$ fragments competent for sequence-specific DNA binding. Oncogne 13: 2077 2086

21. Luetjens CM, Kogel D, Reimertz C, Dussmann H, Renz A, Schulze-Osthoff K, Nieminen AL, Poppe M and Prehn JH (2001) Multiple kinetics of mitochondrial cytochrome $c$ release in drug-induced apoptosis. Mol. Pharmacol. 60: 10081019

22. Yanase N, Ohshima K, Ikegami Hand Mizuguchi J (2000) Cytochrome crelease, mitochondrial membrane depolarization, caspase-3 activation, and Bax-alpha cleavage during IFN-alpha-induced apoptosis in Daudi B lymphoma cells. J. Interferon Cytokine Res. 20: 1121-1129

23. Li P, Nijhawan D, Budihardjo I, Srinivasula SM, Ahmad M, Alnemri ES, Wang X (1997) Cytochrome $c$ and dATP-dependent formation of Apaf-1/caspase-9 complex initiates an apoptotic protease cascade. Cell 91: 479-489

24. Pizer ES, Wood FD, Heine HS, Romantsev FE, Pasternack GR and Kuhajda FP (1996) Inhibition of fatty acid synthesis delays disease progression in a xenograft model of ovarian cancer. Cancer Res. 56: 1189-1193

25. Gorospe M, Wang X, Holbrook NJ (1999) Functional role of p21 during the cellular response to stress. Gene Expr. 7: $377-385$

26. Stiewe T and Putzer BM (2001) p73 in apoptosis. Apoptosis 6: 447-452

27. Davis PK and Dowdy SF (2001) p73. Int. J. Biochem. Cell Biol. 33: 935-939

28. Naka M, Ozaki T, Takada N, Takahashi M, Shishikura T, Sakiyama S, Tada M, Todo S and Nakagawara A (2001) Functional characterization of naturally occurring mutants (P405R and P425L) of p73alpha and p73beta found in neuroblastoma and lung cancer. Oncogene 20: 3568-3572

29. Gong JG, Costanzo A, Yang HQ, Melino G, Kaelin Jr WG, Levrero M and Wang JY (1999) The tyrosine kinase c-Abl regulates p73 in apoptotic response to cisplatin-induced DNA damage. Nature 399: 806-809

30. McPake CR, Tillman DM, Poquette CA, George EO, Houghton JA and Harris LC (1998) Bax is an important determinant of chemosensitivity in pediatric tumor cell lines independent of $\mathrm{Bcl}-2$ expression and p53 status. Oncol Res. 10: 235-244 
31. JurgensmeierJM, Xie Z, Deveraux Q, Ellerby L, Bredesen D and Reed JC (1998) Bax directly induces release of cytochrome $c$ from isolated mitochondria. Proc. Natl. Acad. Sci. USA 95: 4997-5002

32. Desagher S, Osen-Sand A, Nichols A, Eskes R, Montessuit S, Lauper S, Maundrell K, Antonsson B and Martinou JC (1999) Bid-induced conformational change of Bax is responsible for mitochondrial cytochrome $c$ release during apoptosis. J. Cell Biol. 144: 891-901

33. Eskes R, Desagher S, Antonsson B and Martinou JC (2000) Bid induces the oligomerization and insertion of Bax into the outer mitochondrial membrane. Mol. Cell Biol. 20: 929-935

34. Wood DE and Newcomb EW (2000) Cleavage of Bax enhances its cell death function. Exp. Cell Res. 256: 375-382

35. Juhl H, Petrella EC, Cheung N-KV, Bredehorst R and Vogel C-W (1990) Complement killing of human neuroblastoma cells: a cytotoxic monoclonal antibody and its $\mathrm{F}(\mathrm{ab})_{2}$ '-cobra venom factor conjugate are equally cytotoxic. Mol. Immunol. 27: $957-964$

36. Cheung N-KV, Saarinen UM, Neely JE, Landmeier B, Donovan D and Coccia PF (1985) Monoclonal antibodies to a glycolipid antigen on human neuroblastoma cells. Cancer Res. 45: 2642-2649

37. OllertM, Frade R, Fiandino A, Panneerselvam M, Petrella EC, Barel M, Pangburn MK, Bredehorst R and Vogel C-W (1990) C3-cleaving membrane proteinase. A new complement regulatory protein of human melanoma cells. J. Immunol. 144: $3862-3867$
38. Noguchi P, Wallace R, Johnson J, Farley EM, O'Brien S, Ferrone S, Pellegrino MA, Milstien J, Needy C, Browne W and Petricciani J (1979) Characterization of WiDR: a human colon carcinoma cell line. In Vitro 15: 401-408

39. Boukamp P, Petrussevska RT, Breitkreutz D, Hornung J, Markham A and Fusenig NE (1988) Normal keratinization in a spontaneously immortalized aneuploid human keratinocyte cell line. J. Cell Biol. 106: 761-771

40. David K, OllertMW, Vollmert C, Heiligtag S, EickhoffB, Erttmann R, Bredehorst R and Vogel CW (1999) Human natural immunoglobulin M antibodies induce apoptosis of human neuroblastoma cells by binding to a Mr 260,000 antigen. Cancer Res. 59: 3768-3775

41. Laemmli UK (1970) Cleavage of structural proteins during the assembly of the head of bacteriophage T4. Nature 227: 680-685

42. Vermes I, Haanen C, Steffens-Nakken H and Reutlingsperger CJ (1995) A nove assay for apoptosis. Flow cytometric detection of phosphatidylserine expression on early apoptotic cells using fluorescein labelled Annexin V. Immunol. Meth 184: $39-51$

43. Cossarizza A, Baccarani-Contri M, Kalashnikova G and Franceschi C (1993) A new method for the cytofluorimetric analysis of mitochondrial membrane potential using the J-aggregate forming lipophilic cation 5,5',6,6'-tetrachloro$1,1^{\prime}, 3,3^{\prime}$-tetraethylbenzimidazolcarbocyanine iodide (JC-1). Biochem. Biophys Res. Commun. 197: 40-45 